\title{
Owner awareness and knowledge of canine leptospirosis as a zoonotic disease in Morogoro, Tanzania
}

\author{
KHADIJA SAID ${ }^{*}$, ABDUL KATAKWEBA ${ }^{2}$ and ROBERT MACHANG' ${ }^{2}$ \\ 'Department of Veterinary Medicine and Public Health, Sokoine University of Agriculture, P.O. Box 3021, \\ Morogoro, Tanzania \\ ${ }^{2}$ Pest Management Centre, Sokoine University of Agriculture, Morogoro, Tanzania \\ 'Department of Microbiology, Parasitology and Biotechnology, Sokoine University of Agriculture, \\ Morogoro, Tanzania
}

\begin{abstract}
Background: Leptospirosis is a neglected disease of worldwide distribution, affecting both human and animals caused by infection with pathogenic species of the genus Leptospira. This study was carried out to determine the awareness of canine leptospirosis among dog keeping communities in Morogoro, Tanzania.

Methods: Awareness among dog owners for canine leptospirosis was assessed using semi-structured questionnaire among randomly chosen dog owners in Morogoro, Tanzania. Information sought from the dog owners included: awareness of dog diseases in general and specifically canine leptospirosis; clinical signs, transmission, treatment, prevention, and awareness that canine leptospirosis is zoonotic.

Results: A total of 124 dog owners participated in the study. Of these, $90 \%$ were not aware of the existence of canine leptospirosis. Fifteen percent of the participants were not aware that dogs could get disease. The majority of the respondents $(98.4 \%$; $=122)$ did not know the clinical signs of leptospirosis in dogs. The few (1.6\%) who knew mentioned jaundice, bloody diarrhoea, blood in urine, loss of appetite and vomiting as the clinical signs of leptospirosis in dogs. None of the respondents knew how canine leptospirosis is treated, or that the disease is a health risk to humans. Only one respondent $(0.8 \%)$ knew that the control of canine leptospirosis could be achieved through vaccination.

Conclusion: The findings of this study indicate there is little awareness of canine leptospirosis and its potential public health risk among dog owners in Morogoro, Tanzania. The findings of this study indicate the need to raise awareness of the disease among the dog owners and the general population.
\end{abstract}

Keywords: dog, owners, leptospirosis, awareness, knowledge, zoonosis, Tanzania

\section{Introduction}

Leptospirosis is a bacterial zoonotic disease of ubiquitous distribution, which is been considered as re-emerging and neglected in different parts of the world (Chomel, 2014; Allan et al., 2015; Costa et al., 2013). Leptospirosis has been recognized as global public health problem in humans and animals with increased incidence in both low and high income countries (Vijayachari et al., 2008). A report on human leptospirosis burden estimation suggested that Africa is the region with the highest median annual incidence followed by other parts of the world (WHO, 2011). Approximately 300,000 to 500,000 severe cases with case fatality rates of up to $30 \%$ and annual death rate of 58,900 is reported each year globally (Costa et al., 2013). The annual mean incidence rate of leptospirosis in Africa is the highest in the world with 100/100,000 people suffering from this disease (Abgueguen et al., 2008; Sethi et al., 2010;

\footnotetext{
*orrespondence E-mail:khadijasaid31@gmail.com
} 
WHO, 2011). In Africa, although the acute human leptospirosis has been reported in 18 countries (Allan et al., 2015), awareness of this disease is very low in the general public and among health care providers.

Leptospirosis is endemic in Tanzania and has emerged as one of the important causes of febrile illness in humans. An annual incidence of as high as 75-102 cases of leptospirosis per 100,000 people has been reported in northern Tanzania (Biggs et al., 2013). The prevalence has increased from about $0.3 \%$ in 1997 to 30\% in 2015 (Mgode et al., 2016). High prevalence of human leptospirosis have been reported from Kilimanjaro (9-20\%) (Biggs et al., 2011; Crump et al., 2013), Morogoro (10.8\%-13\%) (Mgode et al., 2015); and Katavi regions (29.96\%) (Assenga et al., 2015). Similarly, Leptospirosis in both domestic and wild animals has been reported in Tanzania (Machang'u et al., 1997; Kessy et al., 2005; Mgode et al., 2015). Higher prevalence of Leptospira infection have been reported in cattle (30.37\%), in goats (8.47\%), buffaloes (28.95\%), rodents (20.29\%) and shrews (9.09\%) (Assenga et al., 2015). Other studies in Tanzania have reported high prevalence in pigs (41\%), dogs (39\%), cats (14\%), bats (19.4\%) and freshwater fish (54\%) (Mgode et al., 2014a, b; Mgode et al., 2015). Infected rodents, which are the natural reservoir hosts (Machang'u et al., 2003), serve as the primary source of transmission by shedding of the Leptospira in their urine into the environment, thus contaminating water bodies, from which other animals and humans get the infection.

Dogs have been recognized as potential maintenance hosts and may serve as an important source of infection for humans and other susceptible animals in peridomestic environments (Rojas et al., 2010). One in five dogs die because of complications associated with the infection (Sykes, 2014). Despite the high prevalence of Leptospirosis in both human and animals in Tanzania, the level of awareness among many dog owners, of canine leptospirosis and its zoonotic nature is low. To date, there is no study on the awareness of Tanzanian dog owners about canine leptospirosis and its zoonotic significance. This, lack of awareness can put the dog owners' lives at risk of disease. The aim of this study was therefore to determine the awareness and knowledge of canine leptospirosis in selected communities in Morogoro region, Tanzania.

\section{Materials and Methods}

\section{Study area}

This was a cross sectional study carried out in the three districts of Morogoro region in Tanzania. The district were Mvomero ( $6^{\circ} 14^{\prime} \mathrm{S}, 38^{\circ} 41^{\prime} \mathrm{E}$ ), Morogoro Urban ( $6^{\circ} 49^{\prime} \mathrm{S}, 37^{\circ} 39^{\prime} \mathrm{E}$ ) and Morogoro Rural ( $\left.6^{\circ} 54^{\prime} \mathrm{S}, 37^{\circ} 54^{\prime} \mathrm{E}\right)$. The study was carried out from November 2016 to July 2017. The dog population in the three districts was estimated at 5645 in Mvomero, 4624 in Morogoro Urban and 10,125 in Morogoro Rural (Morogoro Region Report, unpubl). In a recent study the overall seroprevalence of Leptospirosis in dogs the three districts has been reported to be $9.5 \%$ (Said et al., 2018).

\section{Study population and sampling procedure}

The study districts and wards were purposively selected based on the population of dogs, from which a total of 8 wards were surveyed. From the eight wards, two representative villages were selected using a simple random technique. Within a village, a list of households was used as a sampling frame from which 521 households were chosen using Microsoft Office Excel ${ }^{\circledR}$ 2013 generated random numbers.

\section{Data collection}


A semi-structured questionnaire was designed and administered through face-to-face interview to obtain information from the dog owners or their attendants. Both closed and open-ended questions were included in the questionnaire. Information sought from the dog owners included: age, sex, level of education, person taking care of dog, number of dogs, duration of keeping dogs, types of other animals kept and experience in dog keeping. Other information obtained included awareness of dog diseases in general and specifically canine leptospirosis; clinical signs, transmission, treatment, prevention, and awareness that canine leptospirosis is zoonotic. To measure if the dog owners were knowledgeable about canine leptospirosis (also known as Homa ya Mgunda or Homa ya manjano in Kiswahili), most common clinical signs such as fever, jaundice, vomiting, diarrhoea, melena (black tarry faeces), abortion and premature or weak puppies and blood in urine, were described to the dog keeper.

\section{Ethical considerations}

The permission to conduct the study was sought and granted by the Ethical Clearance Committee of the College of Veterinary Medicine and Biomedical Sciences, Sokoine University of Agriculture, Tanzania. Prior informed consent was obtained from the dog owners.

\section{Data analysis}

Data were derived from questionnaires and recorded into Microsoft Office Excel $^{\circledR} 2013$ for statistical analysis. The data were analysed using Epi-Info ${ }^{T M}$ software version 7.1.4.0 (2014). Descriptive statistics particularly frequencies related to dog owners' awareness of canine leptospirosis and its zoonotic importance were generated.

\section{Results}

\section{Socio-demographic characteristics of the respondent}

A total of 124 were involved in this study. Demographic information on all 124 respondents regarding sex, age, level of education, and experience of dog caretakers is summarized in Figure 1. Dog keeping in the family unit was mostly left to children. Dogs were kept for different purposes including security (95\%), pets (4\%) and breeding (1\%). The number of dogs owned ranged from one to eight per household and at least $78.1 \%$ of respondents owned between one and three dogs. Twenty-eight respondents kept only dogs, while others also kept chicken, cattle, pigs, cats, sheep and goats. Among respondents, 55\% commonly appealed to a livestock field officer for primary animal health service provision while the remaining used their own knowledge and experience in handling sick livestock. 


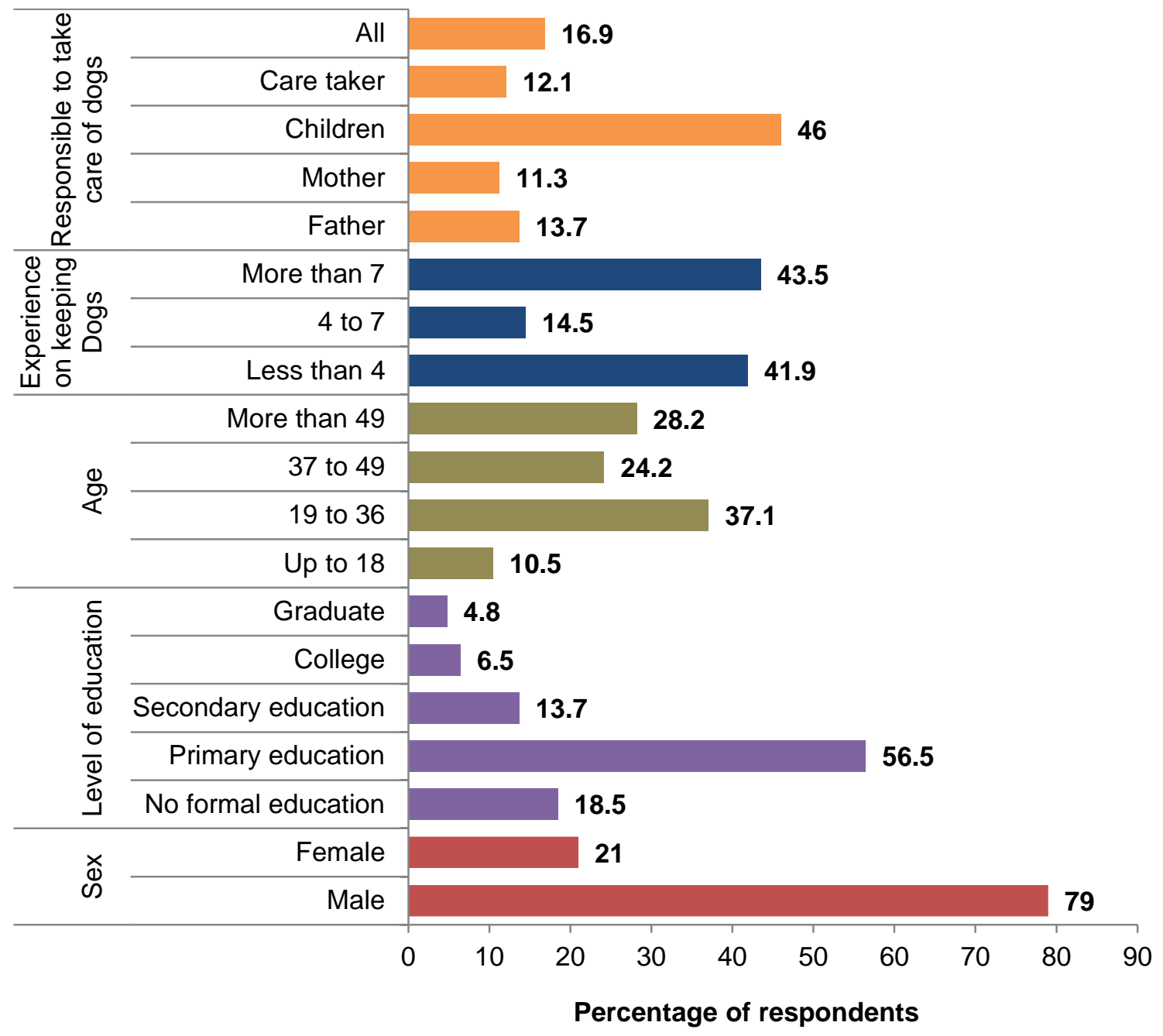

Figure 1: Socio-demographic characteristics of the respondents

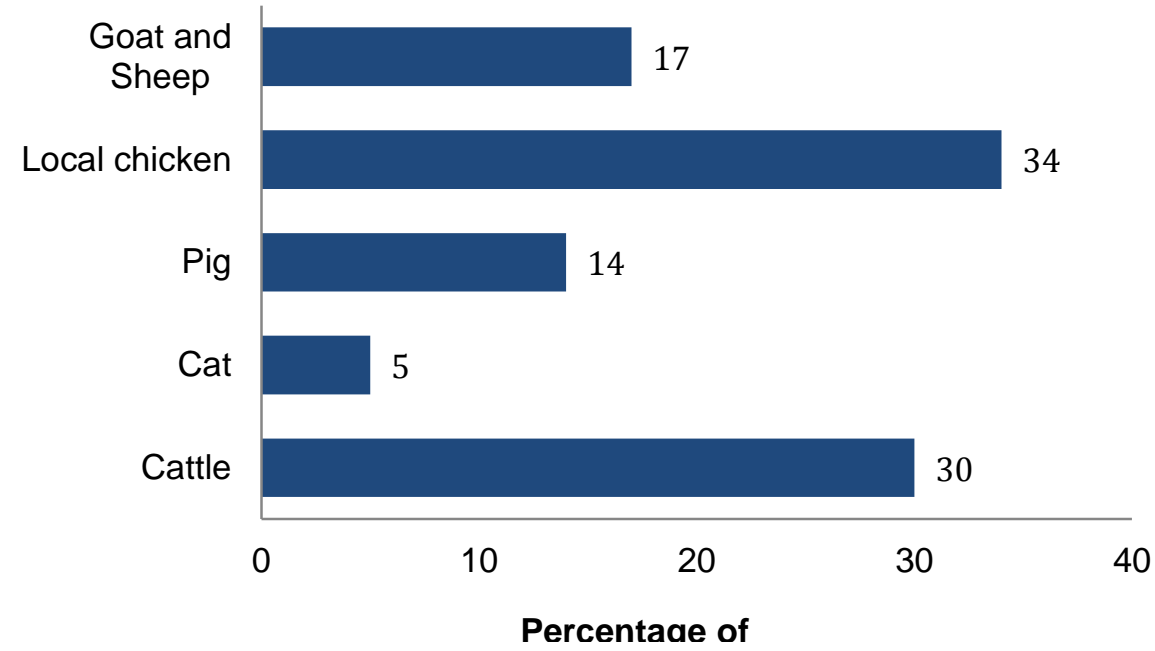

Figure 2: Types of livestock owned by the respondents 


\section{Awareness about canine leptospirosis disease in dogs}

When the respondents were asked if dog ever get sick; the majority (84.7\%) said yes, while $15.3 \%$ said that dogs do not get sick. Those who said dogs can be sick mentioned rabies, worm infestation and mange as the most frequent diseases. Other diseases mentioned by respondents included canine parvovirus, transmissible venereal tumour and flea infestation (Table 1).

Table 1: Dog diseases mentioned by respondents $(\mathrm{N}=124)$

\begin{tabular}{lll}
\hline Disease & Number & Percentage \\
\hline Rabies & 83 & 66.9 \\
Worm infestation & 73 & 58.9 \\
Mange & 48 & 38.7 \\
Canine parvovirus & 5 & 4 \\
Flea infestation & 2 & 1.6 \\
Transmissible venereal tumour & 1 & 0.8 \\
\hline
\end{tabular}

\section{Awareness of dog-owners about canine leptospirosis in dogs}

The survey revealed that majority of respondents $(n=112)$ had never heard of canine leptospirosis. The remaining $(n=12)$ knew about the disease from different sources including neighbours with sick dogs, livestock field officers, veterinarians, brochures, radio and television (Table 2).

Table 2: Source of information about canine leptospirosis $(\mathrm{N}=124)$

\begin{tabular}{lll}
\hline Source of information & Number & Percentage \\
\hline Had never heard of canine leptospirosis & 112 & 98.4 \\
\hline Neighbours/Friends & 4 & 3.2 \\
Field officers & 4 & 3.2 \\
Veterinarians & 2 & 1.6 \\
Brochures & 1 & 0.8 \\
Radio and television & 1 & 0.8 \\
\hline
\end{tabular}

\section{Clinical signs of canine leptospirosis, transmission and control}

When asked about the clinical signs of canine leptospirosis, fever, diarrhoea, loss of appetite, vomiting and blood in urine were mentioned (Table 3). None of the respondents knew how canine leptospirosis is transmitted or controlled. When dog owners were asked if they knew how leptospirosis is transmitted to humans and the effects it has, none knew that it is a zoonosis. However, they knew canine rabies as the only zoonotic disease humans can get from dog bites.

Table 3: Signs and symptoms of canine leptospirosis

\begin{tabular}{lll}
\hline Signs/Symptoms & $\mathbf{n}$ & $\%$ \\
\hline Loss of appetite & 5 & 41.7 \\
Vomiting & 5 & 41.7 \\
Diarrhoea & 2 & 16.7 \\
Fever & 2 & 16.7 \\
Blood in urine & 1 & 8.3 \\
\hline
\end{tabular}




\section{Discussion}

This study was set to determine awareness of the dog owners about canine leptospirosis and as its importance as a zoonotic disease. Our findings show, a general lack of awareness of leptospirosis amongst dog owners/keeper consistent to previous reports from studies in the same region of Tanzania (Mgode et al., 2015). This could be attributed to the low level of education of the respondents. Only about half of the respondents had at least primary school education. Overall, no respondent was aware of canine leptospirosis to be a zoonotic disease. Interestingly, rabies was well known to be a zoonosis. These findings are consistent with those of a study in urban Harare and rural communities in Zimbabwe, where dog owners were aware of rabies as zoonotic disease but not leptospirosis (Dhilwayo et al., 2012). This observation could be due to government putting more emphasis on rabies control through massive campaigns on vaccination of dogs. Furthermore, media gives a wider publicity whenever a rabies case is reported as compared to other dog diseases because of the dramatic clinical signs of the disease. There is need for inclusive publicity and outreach programmes on canine diseases in the communities.

A small percentage of respondents was knowledgeable of canine leptospirosis; and got the information from animal health workers and veterinarians. This could be attributed to poor coverage of veterinary outreach services. A study in Ithaca, New York in the US indicated $40 \%$ of the respondents quoting their veterinarians as their primary source of information on canine diseases (Sandhu \& Singh, 2014). Only a relatively few participants quoted their neighbour/friend or mass media as their sources of information about canine leptospirosis. This observation shows the importance of sharing information among dog owners on the health of their animals. This could be promoted by establishing of kennel clubs, or dog breeding societies in the communities of Morogoro where dog owners could exchange information.

None of the respondents reported having vaccinated against canine leptospirosis although vaccination against rabies was common and strongly supported by government animal health services. This clearly indicates that leptospirosis is a neglected disease even at the national level, and hence an eminent threat of outbreak of this disease in the country. In this study, majority of the dog caretakers were young boys. Children cannot as easily appreciate changes of the health of the household dog as adults do (Steneroden et al., 2011). Commonly children have closer contact with dogs while playing/grooming in the households thus becoming more vulnerable to contract leptospirosis and other diseases (Mboera et al., 1996) from infected dogs. It is therefore recommended that adults in the studied households be urged to take more pro-active role in monitoring the welfare of their animals to avoid transmission of zoonoses.

In conclusion, this study has demonstrated that there is little awareness of canine leptospirosis and its potential public health risk among dog owners in Morogoro, Tanzania. The findings of this study indicate the need to raise awareness of the disease among the dog owners and the general population. This could be done through education and information materials and mass and social media campaigns are important to promote public awareness of leptospirosis to the general population. Further surveys in different areas of Tanzania need to be undertaken to determine the level of awareness of leptospirosis in general, and canine leptospirosis in particular. Leptospirosis being a zoonosis, veterinary and public health authorities should ensure effective partnerships for joint control efforts. 


\section{Competing interests}

The authors declare that they have no competing interests.

\section{Acknowledgements}

The authors wish to thank Georgies F. Mgode and Ginethon G. Mhamphi of the Sokoine University of Agriculture for their advice and technical assistance. The Livestock Officers and the Ward Extension Officers in the study areas are acknowledged for the assistance during the field data collection. We acknowledge the dog owners for their enthusiasms and voluntarily participating in this study. We are also grateful to the Management of Sokoine University of Agriculture for administrative and logistic support. This study received financial assistance from the African Small Companion Animal Network.

\section{References}

Abgueguen, P., Delbos, V., Blanvillain, J., Chennebault, J. M., Cottin, J., Fanello, S., \& Pichard. E. (2008) Clinical aspects and prognostic factors of leptospirosis in adults' Retrospective study in France. Journal of Infection 57: 171-178.

Allan, K.J., Biggs, H.M., Halliday, J.E.B., Kazwala, R.R., Maro, V.P., Cleaveland, S. \& Crump, J.A. (2015) Epidemiology of Leptospirosis in Africa: A Systematic Review of a Neglected Zoonosis and a Paradigm for “One Health" in Africa'. PLoS Neglected Tropical Diseases 9(9): e0003899.

Assenga, J.A., Matemba, L.E., Muller, S.K., Mhamphi, G.G., \& Kazwala, R.R. (2015) Predominant Leptospiral Serogroups Circulating among Humans Livestock and Wildlife in Katavi Rukwa Ecosystem Tanzania' PLoS Neglected Tropical Diseases 9(3):1-14.

Biggs, H.M., Bui, D.M., Galloway, R.L., Stoddard, R., Shadomy, S.V., Morrissey, A.B., Saganda, W. \& Crump, J.A. (2011) Leptospirosis among hospitalized febrile patients in northern Tanzania. American Journal of Tropical Medicine and Hygiene 85: 275-281.

Chomel, B.B. (2014) Emerging and re-emerging zoonoses of dogs and cats animals. Animals (Basel). 4(3): 434-445.

Costa, F., Hagan, J.E., Calcagno, J., Kane, M., Torgerson, P., Martinez-Silveira, M.S., Stein, C., Abela-Ridder, B. \& Ko, A.I. (2015) Global morbidity and mortality of leptospirosis: a systematic review. PLoS Neglected Tropical Diseases 9(9): 0003898.

Biggs, H.M., Hertz, J.T., Munishi, O.M., Galloway, R.L., Marks, F., Saganda, W., Maro, V.P. \& Crump, J.A. (2013) Estimating leptospirosis incidence using hospital-based surveillance and a population-based health care utilization survey in Tanzania. PLoS Neglected Tropical Diseases 7 (12): e2589.

Crump, J.A., Morrissey, A.B., Nicholson, W.L., Massung, R.F. et al. (2013) Etiology of severe non-malaria febrile illness in northern Tanzania: A prospective cohort study. PLoS Neglected Tropical Diseases 7(7): e2324.

Dhliwayo, S., Matope, G., Marabini, L., Dutlow, K. \& Pfukenyi, D.M. (2012) Seroprevalence of leptospirosis in dogs in urban Harare and selected rural communities in Zimbabwe. Onderstepoort Journal of Veterinary Research 79: 1-6.

Kessy, M.J., Machang'u, R.S., \& Swai, E.S. (2005) A microbiological and serological study of leptospirosis among pigs in the Morogoro Municipality Tanzania. Tropical Animal Health and Production 42: 523-530.

Machang'u, R., Mgode, G., \& Mpanduji, D. (1997) Leptospirosis in animals and humans in 
selected areas of Tanzania. Belgian Journal of Zoology 127: 97-104.

Machang'u, R., Mgode, G., Assenga, J., Mhamphi, G., Hartskeerl, R., Goris, M., Cox, C., Weetjens, H.B. \& Verhagen, R. (2003) Characterization of Leptospira isolates from captive giant pouched rats, Cricetomys gambianus. In: Singleton, G.R., Hinds, L.A., Krebs, C.J., Spratt, M.D. ed. Rats Mice and People Rodent Biology and Management, 40-42.

Mboera, L.E.G. \& Maeda-Machang'u, A.D. (1996) Canine dermatophytosis in Morogoro, Tanzania. Tanzanian Veterinary Journal 16: 20-22.

Mgode, G.F., Mbugi, H.A., Mhamphi, G.G., Ndanga, D. \& Nkwama, E.L. (2014a) Seroprevalence of Leptospira infection in bats roosting in human settlements in Morogoro municipality in Tanzania. Tanzania Journal of Health Research 16 (1).

Mgode, G.F., Mhamphi, G.G., Katakweba, A. \& Thomas, M. (2014b) Leptospira infections in freshwater fish in Morogoro Tanzania: a hidden public health threat. Tanzania Journal of Health Research 16 (2).

Mgode, G.F., Machang 'u, R.S., Mhamphi, G.G., Katakweba, A., Mulungu, L.S., Durnez, L., Leirs, H., Hartskeerl, R.A., \& Belmain, S.R. (2015) Leptospira serovars for diagnosis of leptospirosis in humans and animals in Africa: Common Leptospira isolates and reservoir hosts. PLoS Neglected Tropical Diseases, 9(12), 1-19.

Mgode, G.F., Mhamphi, G.G., Katakweba, A.S., Mboera, L.E.G., Machang'u, R.S. (2016) Leptospirosis in Tanzania: a neglected cause of febrile illness that needs attention of the health system. Policy Brief No. SUA/SMPC/PB/001/2016. Sokoine University of Agriculture, Tanzania.

Rojas, P., Monahan, A.M., Schuller, S., Miller, I.S., Markey, B.K. \& Nally, J.E. (2010) Detection and quantification of leptospires in urine of dogs: A maintenance host for the zoonotic disease leptospirosis. European Journal of Clinical Microbiology and Infectious Disease 29:1305-1309.

Said, K., Bakari, G.G., Machang'u, R., Katakweba, A.S. \& Muhairwa, A.P. (2018) Seroprevalence of canine leptospirosis in Urban and Periurban Morogoro Tanzania. African Journal of Microbiology Research 12: 481-487.

Sandhu, G. \& Singh, D. (2014) Level of awareness regarding some zoonotic diseases among dog owners of Ithaca New York. Journal of Family Medicine and Primary Care 3: 418423.

Sethi, S., Sharma, N., Kakkar, N., Taneja, J., Chatterjee, S.S., Banga, S.S. \& Sharma, M. (2010) Increasing trends of leptospirosis in northern India: A clinico-epidemiological study'. PLoS Neglected Tropical Diseases 4:579.

Steneroden, K.K., Hill, A.E. \& Salman, M.D. (2011) Zoonotic disease awareness in animal shelter workers and volunteers and the effect of training. Zoonoses Public Health 58: 449453.

Sykes, J.E. (2014) Leptospirosis. Canine and Feline Infectious Diseases. Ed. St. Louis, M.O. Elsevier Saunders: 474 - 486.

Vijayachari, P., Sugunan, A.P. \& Shriram, A.N. (2008) Leptospirosis: an emerging global public health problem. Journal of Biosciences 33:557-569.

WHO (2011) Report of the Second Meeting of the Leptospirosis Burden Epidemiology Reference Group. World Health Organisation, Geneva Switzerland. 